\title{
EFFECT OF RICE HUSKS AS FILLER IN POLYMER MATRIX COMPOSITES
}

\section{K. Hardinnawirda and I. SitiRabiatull Aisha}

\author{
Faculty of Mechanical Engineering \\ Universiti Malaysia Pahang \\ 26600 Pekan, Pahang, Malaysia \\ Email: rabiatull@ump.edu.my
}

\begin{abstract}
In this study, rice husk-filled polyester composites were produced with rice husks (RH) as the filler and unsaturated polyester resin (UPR) as the matrix. Several percentages of filler loadings were used $(10,15,20$ and $25 \mathrm{wt} \%)$ in order to gain insights into the effect of filler content on the mechanical properties and water intake of the composites. The tensile strength of the RH-filled UPR composites was found to decrease as the filler loading increased; however, as it reached $25 \mathrm{wt} \%$, the strength showed a moderate increase. The Young's modulus showed a remarkable increase for $15 \mathrm{wt} \%$ of RH but decreased as the RH percentage increased further to $25 \mathrm{wt} \%$. A water absorption test was conducted and the results showed that the composites absorb more water as the percentage weight of $\mathrm{RH}$ increased, which is attributed to the ability of the RH filler to absorb water.
\end{abstract}

Keywords: Rice husks, unsaturated polyester resin, water absorption, tensile strength.

\section{INTRODUCTION}

Over recent decades, many polymer composites have been prepared and combined with various types of synthetic reinforcing fillers, in order to improve their mechanical properties and obtain those characteristics demanded by actual applications (Yao, Wu, Lei, \& Xu, 2008; Tabari, Nourbakhsh, \& Ashori, 2011; Bachtiar, Sapuan, \& Hamdan, 2011, Adebisi, Malequ, \& Rahman, 2011). The use of natural fillers for the reinforcement of composites has received increasing attention from both academia and industry. Natural fillers have many significant advantages over synthetic fillers and fibres, such as their light weight, low cost, ability to reduce abrasion of machinery and non-toxicity. Many types of natural fillers have been investigated for use in industry, including: flax, hemp, wood, wheat, barley and oats (Bledzki \& Gassan, 1999). They are now evolving quickly as potential alternatives to inorganic or synthetic materials for various applications, such as in building materials and automotive components (Nourbakhsh, Ashori, Ziaei Tabari, \& Rezaei, 2010; Nourbakhsh, Baghlani, \& Ashori 2011; Jeffrey, Tarlochan, \& Rahman, 2011). Rice husks as fillers have advantages over mineral fillers because they are non-abrasive, require less energy for processing and can reduce the density of furnished products. Hence, these composites have attracted much attention and are becoming increasingly important for the production of a wide variety of cheap, lightweight environmentally friendly composites.

The physical and mechanical properties of natural filler composites are largely dependent on the type of matrix, content and properties of the reinforcement fillers and the filler-matrix interaction. A better dispersion of the filler can be achieved by effective 
mixing of the components and a proper compounding process (Yang, Wolcott, Kim, Kim, \& Kim, 2007). Dhakal, Zhang, \& Richardson (2007) reported that by adding filler to the polymer material, the mechanical properties of the composite, such as the strength, could be enhanced. However, it has also been mentioned that the strength of the composites can be decreased as the percentage of filler added is increased. One of the main concerns for the use of natural fibre or filler-reinforced composite materials is their susceptibility to moisture absorption and the effect of that on their physical, mechanical and thermal properties (Dhakal et al., 2007). All polymer composites absorb moisture in humid atmospheres and when immersed in water. The effect of moisture absorption leads to the degradation of the filler-matrix interface region, which creates poor stress transfer efficiencies and results in a reduction of mechanical properties (Yang, Zeng, Li, Jian, \& Zhang, 1996). In this study, the mechanical properties and the percentage of water absorption of rice husk filler polyester composite are studied using the following values of filler loading: $10,15,20$ and $25 \mathrm{wt} \%$.

\section{EXPERIMENTAL PROCEDURE}

\section{Preparation of Test Samples}

Finely milled rice husks were collected from a local rice mill. Milled rice husks contain many impurities, such as dust, small rice particles and fine sand particles and therefore, need to be cleaned in order to obtain pure rice husks. After cleaning with water, the rice husks were dried in sunlight for 8 hours. Then they were weighed according to the percentages needed $(10,15,20$ and $25 \mathrm{wt} \%)$. Following that, the unsaturated polyester resin and methyl ethyl ketone peroxide (MEPK) catalyst were mixed in a container and stirred well for 3 to 5 minutes. To allow proper dispersion of the fibres within the gellike mixture, the rice husks were added gradually and stirred. Prior to the mixtures being poured into the mould, the mould was initially polished with a release agent to prevent the composites sticking. Finally, once the mixture was in the mould, it was left at room temperature for 24 hours to fully cure and harden.

\section{Mechanical and Physical Testing}

The test was conducted using an Instron Universal Testing Machine at a fixed crosshead speed of $2 \mathrm{~mm} / \mathrm{min}$. Test samples were prepared according to the ASTM D3039 standard with dimensions of $250 \times 25 \times 2.5 \mathrm{~mm}$. Physical properties, such as water absorption, were investigated according to the ASTM D570 standard. The samples were dried in a furnace at $50{ }^{\circ} \mathrm{C}$ for 8 hours and then cooled in a desiccator. Samples of each type of composite were soaked in distilled water at $23{ }^{\circ} \mathrm{C}$ for 24 hours, following which, the samples were removed from the water, patted dry and measured again.

\section{RESULTS AND DISCUSSION}

\section{Tensile Test}

Figure 1 shows the results of the tensile tests of RH-filled UPR composites using various filler loadings. Figure 2 shows the tensile fracture surfaces of the RH-UPR composites using various filler loadings. The graph from Figure 1 shows that the tensile strength of the composites slightly decreased with increasing filler loading due to the 
poor interfacial bonding. The weak bonding between the hydrophilic filler and the hydrophobic matrix polymer obstructs the stress propagation and thus, causes the tensile strength to decrease when the filler loading increases. In addition, poor dispersion causes agglomeration of the fillers as well as decreasing the tensile properties. From the graph, we can see that there was a moderate increase in tensile stress for the $25 \mathrm{wt} \%$ filler loading. This is believed to be due to the filler used acting as a flaw at higher filler mass fractions, because there was a lack of resin that can wet the filler. These results in inefficient stress transfer, leading to a decrease in tensile strength followed by a modest increase with increasing filler contents. In addition, an increase in the filler content also increases the micro-spaces between the filler and the matrix, which weakens the fillermatrix interfacial adhesion. As a result, the values of tensile strength decreased with an increasing filler content in the composite.

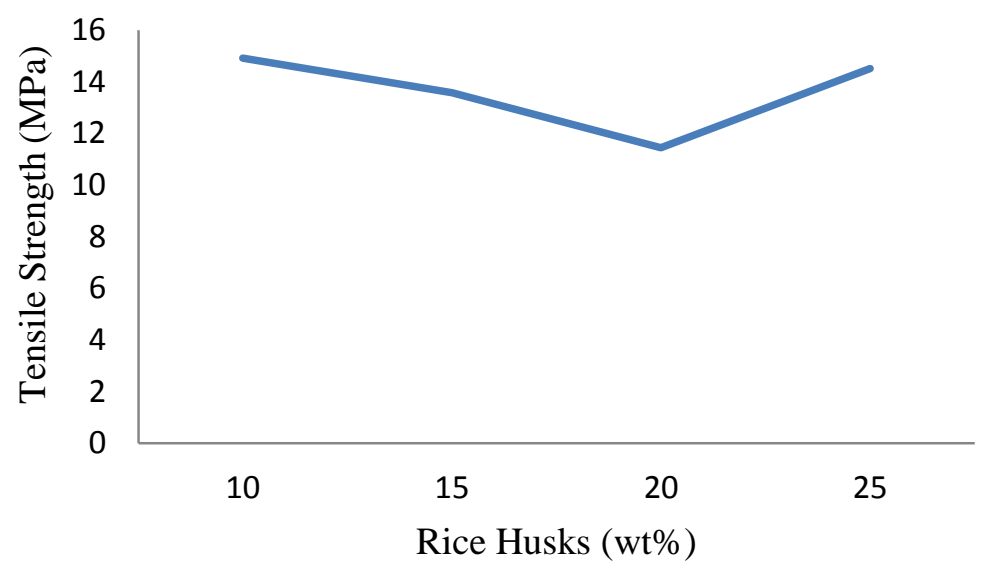

Figure 1.Tensile strengths of RH-filled UPE composites with various filler loadings.
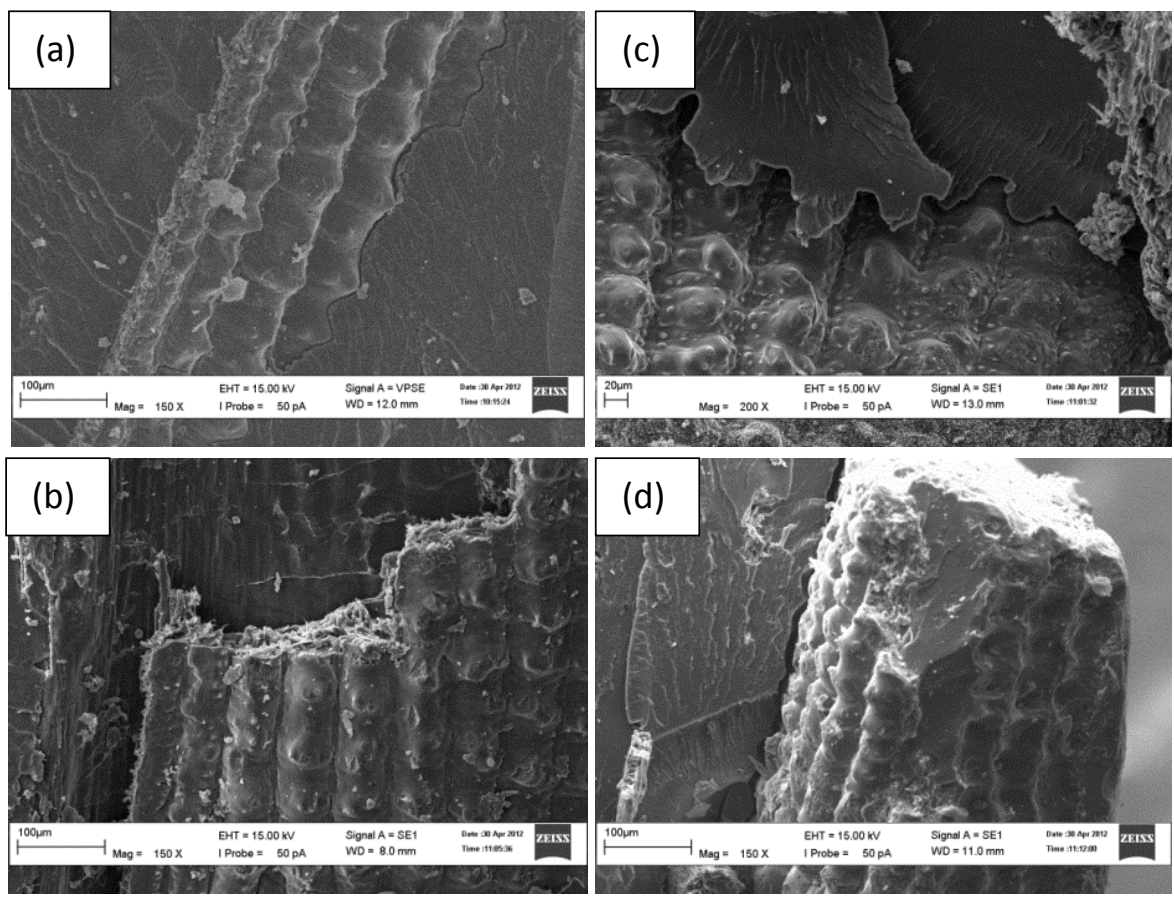

Figure 2.Tensile fracture surfaces of the RH-UPR composites: (a) $10 \mathrm{wt} \%$ of RH-UPR, (b) $15 \mathrm{wt} \%$ of RH-UPR, (c) $20 \mathrm{wt} \%$ of RH-UPR, (d) $25 \mathrm{wt} \%$ of RH-UPR. 
Figure 3 shows filler cracking at various loading conditions. It can be seen that the cracked surface became much more brittle when the percentage of filler was higher. Furthermore, the presence of hydroxyl groups in the cellulose of the rice husks is responsible for its inherent hydrophilic nature. As a result, it became difficult to mix hydrophilic rice husks with hydrophobic UPR. This will also lead to inefficient composites with weak interfacial bonding. Figure 4 shows the variation of the Young modulus of the composite for different filler loading. As the filler loading increased to 15 wt \%, the Young modulus shows a remarkable increase. However, as the filler loading is increased further, the Young modulus of the composites decreases; similar results have been reported by Aramide, Oladele, and Folorunso (2009). In addition, the Young modulus of the composites decreased after exceeding the threshold value, which is $1609.55 \mathrm{MPa}$. This shows that the stiffness of the composites is attained predominantly from the inherent stiffness of the rice husks and the UPR matrix (Rozman, Yeo, Tay, \& Abubakar, 2003).
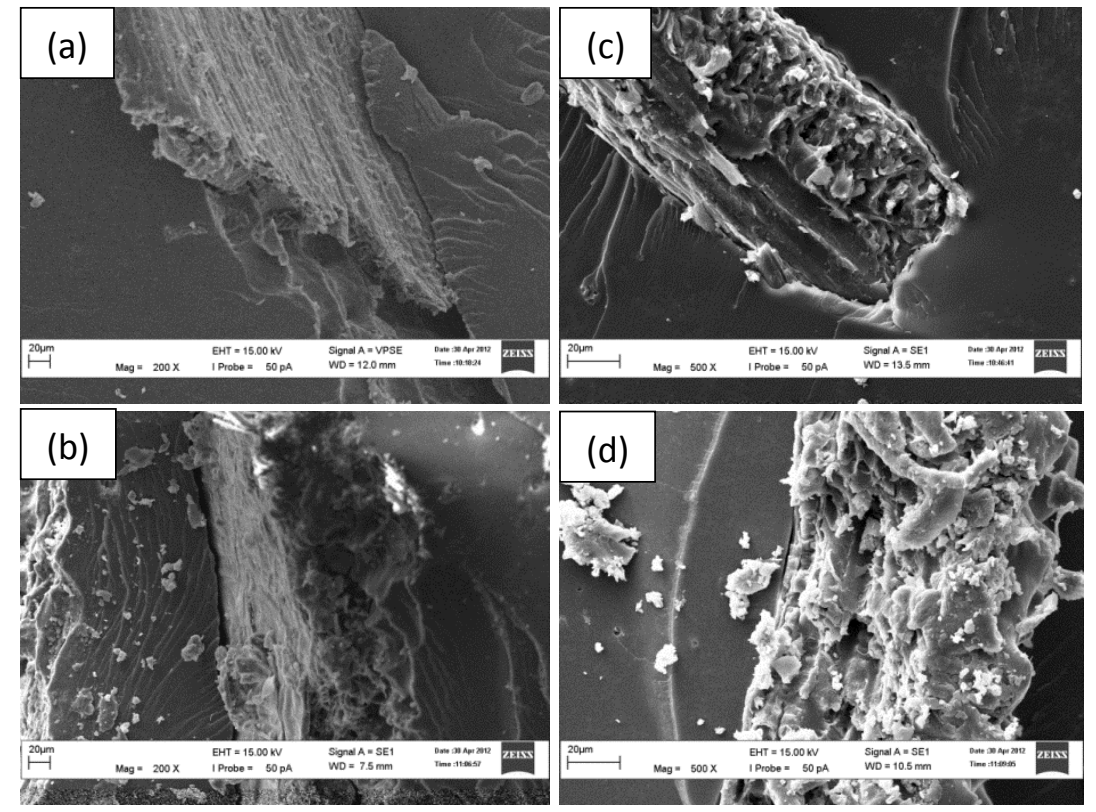

Figure 3. Filler cracking: (a-b) 10 wt \% of RH-UPR, (c-d) 20 wt \% of RH-UPR.

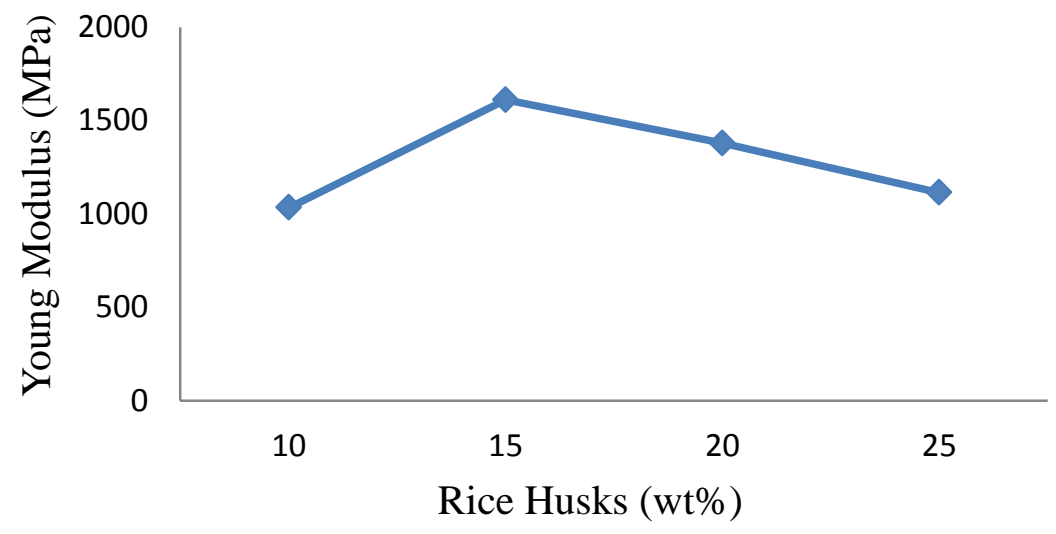

Figure 4.Young modulus of RH-filled UPE composites with various filler loadings. 


\section{Water Absorption}

Figure 5 shows the percentage of water uptake for the RH-filled UPR composites at different filler loadings. The water absorption also increased when the filler loading increased. This is due to the presence of voids in the natural filler polymer composites. These voids form because of the poor adhesion between the matrix and the filler, which in this case was the rice husks, also known as lignocellusoic material. When the natural filler composites are exposed to moisture, the hydrophilic rice husks swell, which leads to the micro cracking of the brittle thermosetting resin. As the composites crack, the capillarity becomes active and hence, the water molecules are actively attracted to the interface, which in turn results in the de-bonding of the filler and matrix. The high cellulose of the rice husks contribute to additional water penetration into the interface through micro-cracks induced by swelling of the filler, which also creates stress and ultimately, leads to failure of the composite.

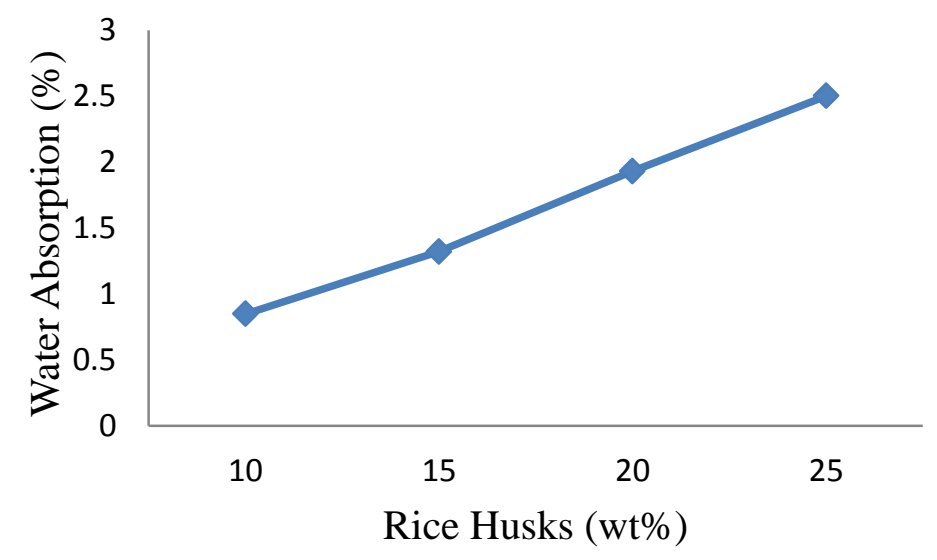

Figure 5. Effect of various filler loadings on water absorption.

\section{CONCLUSION}

From this study, it can be concluded that the tensile strength of the composites decreased when the filler loading was increased. This is due to weak interfacial adhesion between the filler and the matrix caused by porosity and micro cracking. The Young modulus also decreased when the filler loading was increased, except for a loading of $15 \mathrm{wt} \%$, at which point the Young modulus increased remarkably. Additionally, as the filler loading was increased, the composites tended to absorb more water because rice husks are known as a lignocellusoic material.

\section{REFERENCES}

Adebisi, A. A., Maleque, M. A., \& Rahman, M. M. (2011). Metal matrix composite brake rotor: historical development and product life cycle analysis. International Journal of Automotive and Mechanical Engineering, 4, 471-480.

Aramide, F. O., Oladele, I. O., \& Folorunso, D. O. (2009). Evaluation of the effect of fiber volume fraction on the mechanical properties of a polymer matrix composites. Leonardo Electronic Journal of Practices and Technologies, 14, 134141. 
Bachtiar, D., Sapuan, S. M., \& Hamdan, M. M. (2010). Flexural properties of alkaline treated sugar palm fibre reinforced epoxy composites. International Journal of Automotive and Mechanical Engineering, 1, 79-90.

Bledzki, A. K., \& Gassan, J. (1999). Composites reinforced with cellulose based fibres. Progress in Polymer Science, 24, 221-274.

Dhakal, H. N., Zhang, Z. Y., \& Richardson, M. O. W. (2007). Effect of water absorption on the mechanical properties of hemp fibre reinforced unsaturated polyester composites. Composites Science and Technology, 67, 1674-1683.

Jeffrey, K. J. T., Tarlochan, F., \& Rahman, M. M. (2011). Residual strength of chop strand mats glass fiber/epoxy composite structures: effect of temperature and water absorption. International Journal of Automotive and Mechanical Engineering, 4, 504-519.

Nourbakhsh, A., Ashori, A., Ziaei Tabari, H., \& Rezaei, F. (2010). Mechanical and thermochemical properties of wood-flour polypropylene blends. Polymer Bulletin, 65(7), 691-700.

Nourbakhsh, A., Baghlani, F. F., \& Ashori, A. (2011). Nano-SiO 2 filled rice husk/polypropylene composites: Physico-mechanical properties. Industrial Crops and Products, 33, 183-187.

Rozman, H. D., Yeo, Y. S., Tay, G. S., \& Abubakar, A. (2003). The mechanical and physical properties of polyurethane composites based on rice husk and polyethylene glycol. Polymer Testing, 22(3), 6:17-623.

Tabari, H. Z., Nourbakhsh, A., \& Ashori, A. (2011). Effects of nanoclay and coupling agent on the mechanical, morphological, and thermal properties of wood flour/polypropylene composites. Polymer Engineering and Science, 51(2), 272277.

Yang, G. C., Zeng, H. M., Li, J. J., Jian, N. B., \& Zhang, W. B. (1996). Relation of modification and tensile properties of sisal fiber. ACTA Science National University Sunyatseni, 35, 53-57.

Yang, H. S., Wolcott, M. P., Kim, H. S., Kim, S., \& Kim, H. J. (2007). Effect of different compatibilizing agents on the mechanical properties of lignocellulosic material filled polyethylene bio-composites. Composite Structures, 79(3), 369375.

Yao, F., Wu, Q., Lei, Y., \& Xu, Y. (2008). Rice straw fiber-reinforced high-density polyethylene composite: effect of fiber type and loading. Industrial Crops and Products, 28(1), 63-72. 